\title{
EDITORIAL
}

\section{Tecno-Adicciones en jóvenes, adolescentes y niños}

\author{
Verónica Marín-Díaz \\ vmarin@uco.es \\ Universidad de Córdoba, España
}

La presencia de Internet en general y de las herramientas que han ido naciendo, creciendo y desarrollándose a su amparo en particular, han puesto de relieve que hoy nos relacionamos con nuestros semejantes de manera muy diferente a hace 20 años.

Hace dos décadas no imaginábamos que pudiéramos hablar o mantener un conversación fluida a cualquier hora del día y en cualquier lugar con otra persona que no estuviera en nuestro entorno cercano, o que no dispusiera de un teléfono digamos convencional, pues la generalización de los teléfonos móviles ha sido a partir de finales de la década de los 90 principio de 2000 cuando fueron encontrando un crecimiento tecnológico y una gran aceptación social.

En este sentido, comprobamos que la forma en que nos relacionamos ha ido cambiando en la medida en que las tecnologías han ido siendo mejoradas han permitido que los dispositivos que utilizamos de un lado hayan bajado de coste y de otro estén o tengan una gran presencia en nuestro quehacer diario. De entre todos los recursos que mayor penetración tiene hoy en la sociedad, sin duda alguna, es Internet la que se presenta como ganadora ante las demás, y junto a ella los dispositivos así como las herramientas que la utilizan para poder realizar diversas actividades.

Por otra parte, ese auge de Internet ha supuesto que hoy se hable de un lado oscuro que esta tiene. No queremos referirnos a la denominada «red oscura», si no, a los aspectos perniciosos que puede conllevar bien una presencia elevada en las redes sociales, o bien pasar muchas horas jugando delante de una pantalla, por poner unos ejemplos. Hablamos de un trastorno de conducta denominado Tecno-adicción.

El consenso en torno a la tecno-adicción es variopinto en la comunidad científica, pues ni el propio manual de Psicología lo concreta como tal. Encontramos una línea de trabajo de más que hablar de adicción se centra en hablar de un uso problemático de, si bien es claro que las tecno-adicciones presentan los mismos síntomas que una adicción farmacológica, podemos considerar que el papel social que tienen es una variable que juega en contra de poder hablar con rotundidad de un trastorno de conducta digital.

El presente monográfico trata de exponer los estudios realizados en torno a las posibles conductas adictivas, o que no han llegado a ser catalogadas como adicción y se entienden como uso problemático de dispositivos digitales, que los jóvenes, niños y adolescentes de la sociedad del siglo XXI pueden presentar o ya manifiestan tener.

Conformado por 10 artículos, se hace un recorrido por las etapas educativas de Educación Primaria, Secundaria y la universitaria, proporcionando un mapa del estado actual de las posibles conductas tecno-adictivas que niños, jóvenes y adolescentes presentan hoy. 
En este sentido encontramos abriendo el monográfico el artículo firmado por Carbonell et al. En este se hace un recorrido por las tres tecnologías que a día de hoy pueden generar más controversia en torno a hablar de adicción o de uso problemático. Se detiene de manera profusa en poner en cuestión las redes sociales, los videojuegos y el uso de los Smartphone. Es significativo que los autores partan de la metáfora de nuestro querido y entrañable Quijote y su relación con la imprenta, para extrapolar al momento actual la relación que hoy se mantiene con dichos dispositivos. Cierra su artículo con una afirmación que he querido traer aquí pues en gran medida puntualiza la línea de trabajo de la que debemos tratar de priorizar: «parece que lo más sensato es orientar y educar sobre los usos adecuados de las tecnologías digitales en cuanto al tiempo invertido, el lugar donde se utiliza o los fines a los que se destina sin caer en el error de considerarlas una adicción».

Abrimos una primera parte de la mano del artículo firmado por Ruíz de Miguel, Domínguez y Rodríguez, el cual abarca desde la etapa de Educación Primaria hasta la Universitaria, nos acerca a la percepción que estos niños, adolescentes y jóvenes tienen de su relación con los teléfonos inteligentes. En sus resultados hay que destacar que aún los más jóvenes estos no perciben tener conductas de riesgo, a diferencia delo que la literatura y otros estudios que forman parte de este monográfico, han alcanzado. A diferencia por ejemplo del trabajo de Marín-Díaz y SampedroRequena, Ruíz de Miguel et al., ponen de relieve que los estudiantes más jóvenes no consideran tener un problema de adicción, mientras que en el de Marín-Díaz et al sí parecer ser. Ello puede ser, como señala Ruíz de Miguel, que los más jóvenes (alumnado de Educación Primaria) aún tienen el peso de la supervisión de los progenitores, y que esto es una variable significativa, que debería ser estudiada. En este sentido el artículo firmado por González, Quintero y Reche pone de relieve la presencia de la familia. Ello lo abordaremos más adelante.

Continuamos en este monográfico dando una visión a la etapa de la adolescencia. En ella encontramos la propuesta firmada por Cebollero, quien introduce la variable familia en la relación entre la red y los jóvenes. En su artículo nos presenta los resultados logrados en un estudio llevado a cabo con adolescentes, pretende dar las pistas para el desarrollo de estrategias de prevención por parte de los profesores así como de las familias de cara al desarrollo de una correcta y positiva relación entre aquellos e Internet y se puedan determinar las conductas tanto de riesgo como nocivas entre los adolescentes y la red.

En esta línea el trabajo segundo firmado por Raposo-Rivas, Martínez-Figueira y Sarmiento-Campo, nos sitúa ante un nuevo desafío al indicarnos 6 factores que de alguna manera interfieren en la relación adolescente tecnología. Si bien nos señalan que los participantes en su estudio han reflejado que inicialmente los jóvenes emplean la red para la adquisición y transferencia de datos. Es al adentrarnos en su presencia en las redes sociales cuando los 6 factores señalados, toman capital relevancia al dibujar el perfil de presencia en las redes de estos jóvenes. Cierran su aportación incidiendo en la necesidad de promover una formación que permita saber qué es correcto y qué conducta no lo es.

En la segunda parte del monográfico se pone el acento en la esfera universitaria, donde podremos leer el artículo firmado por Marín-Díaz y Sampedro-Requena, el cual nos presenta las percepciones que los educadores sociales en formación tienen de sí mismos en el ámbito digital, en concreto como piensan que es su relación con Internet. En este caso los resultados alcanzados por las autoras reflejan que estos estudiantes universitarios no consideran tener una conducta adictiva de Internet, sin embargo son los más jóvenes los que si presentan ciertos rasgos de ello.

En línea con este trabajo se presenta la aportación de Ruiz-Palmero, Colomo-Magaña, SánchezRivas y Linde-Valenzuela. En este caso se hace un pequeño estudio con maestros en formación de la Universidad de Málaga (España) sobre la autopercepción que tienen sobre el uso de Internet y de los dispositivos móviles tipo Smartphone, videojuegos y redes sociales. Es llamativo que los 
estudiantes señalan no presentar una conducta adictiva ni problemática de dichos elementos antes de estar en confinamiento provocado por el virus SARCOV-2, sin embargo los resultados vinculados a dicho período de tiempo, destacan estos autores que «el uso excesivo del móvil podría ser considerado como un factor de riesgo y un indicador de adicción a redes sociales», concluyendo que es necesario tomar perspectiva de estos y profundizar en el estudio derivado de dicho periodo de restricción de la movilidad.

Siguiendo los estudios con estudiantes universitarios encontramos el trabajo firmado por Martínez et al. Los autores realizan un estudio den diversas comunidades autónomas (Andalucía, Asturias, Castile-Leon, Cataluña, Galicia, Murcia and el País Vasco) de España. Para este trabajo emplearon la adaptación al español del Social Media Addiction Scale-Student Form de Sahin (2018), el cual arrojó que los alumnos universitarios no consideran tener un problema de adicción a las redes sociales. No obstante, al igual que los resultados del estudio que presentan Marín-Díaz y Sampedro-Requena, son los más jóvenes los que perfilan una conducta que se acerca a la adicción.

Cierra la sección del monográfico referente a alumnado universitario, una perspectiva internacional que nos aportan dos trabajos, una desde Colombia y otra desde México. La primera de ellas firmada por Vega, Muñoz y Arancibia. Quienes trae a la palestra la dualidad de hablar de uso problemático o adicción a raís de los resultados alcanzados tras la aplicación del Internet Addiction Test (IAT) de Young con estudiantes universitarios colombianos. Es significativo que en este trabajo los alumnos han puesto de relieve, nuevamente, que consideran tener un uso problemático de Internet, y no una adicción. Nos llama la atención que en este contexto también los discentes más jóvenes son los que se auto perciben con un uso problemático, con lo cual vemos que la variable edad es un elemento que determina esta situación de tecno-adicción.

Desde México, Valencia-Ortiz, Cabero y Garay, realizan un trabajo aplicando la técnica de los grupos nominales con alumnado de los últimos años de Bachillerato y de los primeros universitarios que junto con profesores y orientadores de instituciones mexicanas señalan la necesidad de que exista una regulación del tiempo que se pasa en las redes sociales en particular y con las tecnologías en general. Estos autores, dan un paso más al indicar que la adicción a las redes sociales viene provocada por la propia desarrollada a los dispositivos inteligentes tipo Tablet o Smartphone.

Como ya hemos señalado anteriormente, la figura de la familia cobra relevancia en el trabajo para prevenir una tecno-adicción o tratarla. Así en este monográfico se cierra con el trabajo de González et al. El cual gira en torno a la visión que las familias tienen del uso que sus hijos adolescentes tienen de las tecnologías. En general el trabajo ha puesto de relieve la preocupación de los progenitores y tutores por el elevado número de horas que pasan conectados a redes sociales 0 consumiendo su tiempo delante de una pantalla jugando entre otros aspectos. Por otra parte, también consideran que no es negativo que sus hijos estén conectados o hagan un uso excesivo de las redes sociales en lo que se refiere a mantener contactos con iguales, si les preocupa que estos no se desarrollen dentro de un entorno seguro.

Para finalizar señalar el punto en común que tienen todas estas investigaciones, que no es otra que la formación, la educación para un consumo responsable de los recursos digitales y de los medios así como de los dispositivos. Por tanto ahora queda plantear quién es o debe ser el responsable de no solo diseñar dicha capacitación, sino también quién se encarga de promocionarla y que haya una alta participación. 